\title{
Taking the naturalness out of natural disasters
}

\author{
Phil O'Keefe, Ken Westgate and Ben Wisner argue \\ the case that disasters are more a consequence of \\ socio-economic than natural factors
}

$\mathrm{T}$

HE MEDIA continually present us with graphic accounts of natural disasters-the Bangladesh cyclone, the Nicaraguan earthquake and the African drought are just some of the recent examples of catastrophes that caused much death and destruction. Since the beginning of 1976 , we have already had detailed accounts of floods in Venezuela, Australia and Indonesia, famine in Niger, landslides in Ecuador, drought in Malaysia and the mammoth earthquake in Guatemala. It is difficult to gather global information on the frequency and, more importantly, the impact of these disasters. But a set of global statistics from all available resources has recently been compiled.

The Disaster Research Unit at the University of Bradford has collected data from international organisations, government departments, academic institutions and insurance companies. The information was confused because most institutions recording disaster data had an implicit role in the disasters and their aftermath which coloured their recording. For example, the international and governmental organisations were chiefly concerned with disasters in which aid was being donated, academic institutions were primarily interested in recording unusual phenomena which might not necessarily be disastrous, while insurance companies only recorded information directly related to their business. In spite of the data's unreliability, several tendencies can be observed.

The most important tendency is an increase in the occurrence of disasters over the last 50 years. Figure 1 shows this increase from $1947-70$ of largescale disasters, that is, those disasters covering more than a ten-degree square on a world map and where damage exceeds $\$ 1$ million. This tendency is paralleled by an increasing loss of life per disaster. The greatest loss of life per disaster is observed in underdeveloped countries, and there are general indications that the vulnerability of these countries in particular is increasing. Such conclusions clearly

Phil O'Keefe and Ken Westgate are at the Disaster Research Unit, University of Bradford. Ben Wisner is at the Institute of Development Studies, University of Sussex. require further explanation.

Disaster marks the interface between an extreme physical phenomenon and a vulnerable human population. It is of paramount importance to recognise both of these elements. Without people there is no disaster. The two elements are basic to an explanation of an increase in the occurrence of disasters. No major geological or climatological changes over the last 50 years adequately explain the rise. There is little argument about geological change, but there has been much mystifying argument about climatic change, especially following the prolonged drought over the African and Asian continents. But no firm conclusion can be drawn about changing climatic conditions from available evidence. Randall Baker at the Development Studies School of the University of East Anglia recently reviewed all the evidence of climatic change in Africa, and offered the Scottish judgment of "case not proven". Even if some long-term change was observable it would not explain the increase in disaster occurrence observed in the data.

If it is accepted that there has been no major geological and climatological change in recent years, then it can be assumed that the probability of the extreme physical occurrence is constant. If the probability is constant, then logically the explanation of the increasing numbers of disasters must be sought in an explanation of the growing vulnerability of the population to extreme physical events. Ongoing research suggests that some radical rethinking on the nature of "natural" disasters is necessary.

It is known that the frequency of natural disasters is increasing especially in underdeveloped countries. Indeed, the increased vulnerability of people to extreme physical events can be seen as intimately connected with the continuing process of underdevelopment recorded throughout the world. As population continues to expand, and as resources continue to be controlled by a minority, the real standard of living drops for much of the world's population. This population is increasingly vulnerable to environmental variation as the process continues. Paul Richards of the Environmental Unit in the International African Institute recently

\section{Sorry, for copyright reasons some images on this page may not be available online}

emphasised this in his introduction to African Environment: Problems and Perspectives: " . . . just as natural processes such as lack of rainfall affect social structures", he argued, "so social processes such as economic 'development' can affect natural systems, 'causing' famine and soil erosion for example". He went on:

"[I]n a continent where international ties of dependency, massive international labour migration and multinational companies prevail and in a world where growth does not necessarily mean development, and development does not necessarily bring enrichment or an increase in personal happiness, the ultimate cause of environmental problems may well be traceable to the structural imbalances between rich and poor countries and we would be right to replace the term natural with the more appropriate term social or political disaster".

These suggestions would strike the Guatemalan peasant as commonsense. The recent earthquake there is no longer identified as a natural eventthe local inhabitants who survived are referring to the event as a "classquake". It is a view which reflects their broad experience. That experience is the basis for an explanation of their general plight in terms of a process, not of development, but of underdevelopment -a process which their increasing vulnerability reflects. Instead of moving independently (as one school of thought argues) from a state of undevelopment to development along the lines that the now-developed west has already done, Third World countries (says an alternative, radically opposed school) have in fact been moving retrogressively from a state of undevelopment to one of underdevelopment, in a process of "marginalisation" which is not so much separate from as the price of the west's development in an increasingly inter- 
dependent world. As this has happened, the relatively deprived sectors of the populations within these countries have become even worse off.

The reality of this situation is shown in Figure 2. It is the poorest countries which tend to suffer most disaster strikes. This point ought to encourage precautionary planning to mitigate the effect of future disaster. Such precautionary planning needs to be totally integrated into planning for real development, which means the necessary concentration on the vulnerability of a population to future disaster can only be done successfully through an understanding of the marginalisation process. Emphasis on precautionary planning does not, of course, make unnecessary the valuable action invariably mounted in the aftermath of a disaster: in fact, the formation of the London Technical Group, which supplies accurate technical reports on the position after disasters and generally provides expertise on relief measures, is to be warmly welcomed. In the long run, however, precautionary planning would be more beneficial than relief work, since it would aim to consider and alleviate the causes and not merely the symptoms of disaster.

Successful precautionary planning, then in focusing on the population's vulnerability, depends upon the identifi-

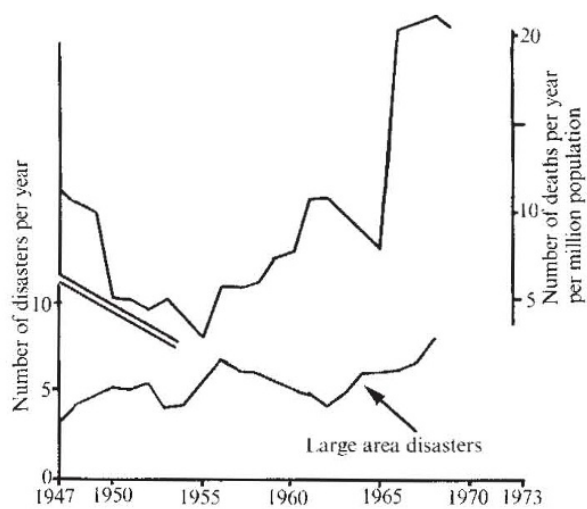

Fig. 1 Global disasters 1947-1973 : Five-year moving average.

cation of cultural attitudes towards the use of indigenous resources at local and regional levels, and the incorporation into development planning of strategies to mitigate disasters; precautionary planning should be seen as the insurance chapter in any development plan. The aim would be to raise the standards of life of people currently ill-placed to resist disasters because those standards are too low. The average "cost" of a disaster strike, a rather meaningless concept when the range of impact is so great, is about $\$ 20$ million. It is sufficient to say that

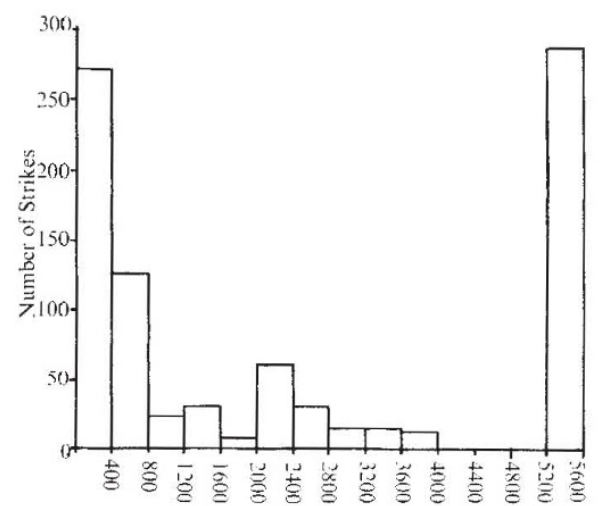

Fig. 2 Number of disaster strikes by per capita income of disaster-strike area: the large number of disasters recorded in developed countries is a reflection of the closer monitoring of disaster events.

more than $\$ 1,100$ million was spent on disaster assistance in 1973; and 96 countries of the world had less than this amount of resource capital as GNP in 1973. The time is ripe for some form of precautionary planning which considers vulnerabliity of the population as the real cause of disaster - a vulnerability that is induced by socio-economic conditions that can be modified by man, and is not just an act of God. Precautionary planning must commence with the removal of concepts of naturalness from natural disasters.

\section{Sorry, for copyright reasons some images on this page may not be available online}

